\title{
An Ammonium Bicarbonate-Enhanced Stable Isotope Dilution UHPLC-MS/MS Method for Sensitive and Accurate Quantification of Acrolein-DNA Adducts in Human Leukocytes
}

\author{
Ruichuan Yin, ${ }^{\dagger}$ Shengquan Liu, ${ }^{\dagger}$ Chao Zhao, ${ }^{\dagger}$ Meiling Lu, ${ }^{\dagger, \dagger}$ Moon-shong Tang, ${ }^{\S}$ and Hailin Wang ${ }^{*}{ }^{\dagger}$ \\ ${ }^{\dagger}$ State Key Laboratory of Environmental Chemistry and Ecotoxicology, Research Center for Eco-Environmental Sciences, Chinese \\ Academy of Sciences, Beijing, 100085, China \\ ${ }^{\ddagger}$ Chemical Analysis Group, Agilent Technologies, Beijing, 100102, China \\ ${ }^{\S}$ Department of Environmental Medicine, Pathology and Medicine, New York University School of Medicine, Tuxedo Park, New \\ York 10987, United States
}

ABSTRACT: Acrolein (Acr), a ubiquitous environmental pollutant, can react directly with genomic DNA to form mutagenic adducts without undergoing metabolic activation. To sensitively and accurately quantify Acr-DNA adducts (including structural isomers and stereoisomers) in human leukocytes, we developed an enhanced stable isotope dilution ultrahigh performance liquid chromatography (UHPLC)-tandem mass spectrometry (MS/MS) method using ammonium bicarbonate $\left(\mathrm{NH}_{4} \mathrm{HCO}_{3}\right)$, which is thermally unstable and degrades readily to carbon dioxide and ammonia in heated gas phase. Interestingly, ammonium bicarbonate (as an additive to the mobile phase) not only improves the protonation of AcrdG adducts but also suppresses the formation of MS signal-deteriorating metal-AcrdG complexes during electrospray ionization, leading to the enhancement of their MS detection by $2.3-8.7$ times. In contrast, routinely used ammonium salts (ammonium acetate and ammonium formate) and formic acid do not show similar enhancement. The developed method is potentially useful for enhancing ESI-MS detection of other modified 2'deoxyribonucleosides that have difficulty in protonation and may form excess metal complexes during electrospray ionization. The limits of detection (LODs, $\mathrm{S} / \mathrm{N}=3$ ) are estimated to be about 40-80 amol. By the use of the developed method, we found that the Acr adducts of three nucleotides $(\mathrm{dG}, \mathrm{dA}$, and $\mathrm{dC}$ ) can be detected in human leukocytes. In addition to the known $\gamma$ AcrdG, $\alpha$-AcrdA is also identified as an Acr-adduct of high abundance (2.5-20 adducts per $10^{8}$ nts).
A crolein (Acr) is one of the most reactive and harmful $\alpha, \beta$ unsaturated aldehydes and is found in cigarette smoke, ${ }^{1,2}$ the volatiles generated during cooking, ${ }^{3}$ and automobile exhaust. ${ }^{4}$ Acr has been proposed as the major carcinogenic agent responsible for cigarette-related lung cancer, replacing the well-known carcinogen benzo $(\alpha)$ pyrene. ${ }^{5}$ Moreover, Acr can be endogenously produced during peroxidation of polyunsaturated fatty acids ${ }^{6,7}$ and degradation of amino acids ${ }^{8}$ and polyamines. ${ }^{9}$ Elevated levels of Acr were found in vulnerable brain regions of subjects with wild cognitive impairment ${ }^{10}$ and preclinical $^{11}$ and late-stage Alzheimer's disease (AD). ${ }^{12,13}$ Endogenously produced Acr may play an important role in the pathogenesis of $\mathrm{AD}^{10-13}$ and cardiovascular diseases. ${ }^{14}$ Currently, it is not clear how Acr causes these pathogenic effects. Because Acr can react directly with the bases of genomic DNA due to its strong electrophilicity, the formation of stable Acr-DNA adducts may play essential roles in the pathogenesis of Acr.

The reaction of Acr with guanine in genomic DNA can produce two structural isomers of exocyclic adducts (Figure 1): 6-hydroxy-1, $N^{2}$-propano-2'-deoxyguanosine $(\alpha$-AcrdG) and 8 hydroxy-1, $N^{2}$-propano-2'-deoxyguanosine adducts $(\gamma$ -
AcrdG) ${ }^{15}$ Meanwhile, $\alpha$-AcrdG has two mutually convertible stereoisomers. Both $\alpha$ - and $\gamma$-AcrdG are mutagenic in bacteria $^{16,17}$ and mammalian cells. ${ }^{18,19}$ In human cells, AcrdG mainly induces mutations of G:C to T:A or A:T. ${ }^{18,19}$ In an early report, $\gamma$-AcrdG could be detected in human tissues without Acr treatment, but $\alpha$-AcrdG was not detectable in most samples. ${ }^{20,21}$ The levels of $\gamma$-AcrdG in smokers are significantly higher than that in nonsmokers. ${ }^{22}$ Recently, both $\alpha$-AcrdG and $\gamma$-AcrdG could be detected in human placenta, leukocytes, and lung tissues by LC-MS/MS analysis. ${ }^{23,24}$ Inconsistently, the levels of $\alpha$-AcrdG in human lung were found to be even higher than that of $\gamma$-AcrdG. ${ }^{24}$ What factors contributed to such inconsistency is not clear. Nonetheless, an advanced analytical method for accurate and sensitive quantitation of Acr-DNA adducts is highly desirable, particularly for the minor but highly mutagenic $\alpha$-AcrdG.

Received: November 29, 2012

Accepted: February 22, 2013

Published: February 22, 2013 


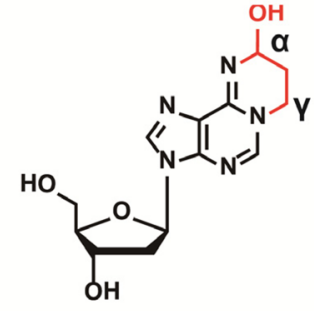

$\alpha-A c r d A$

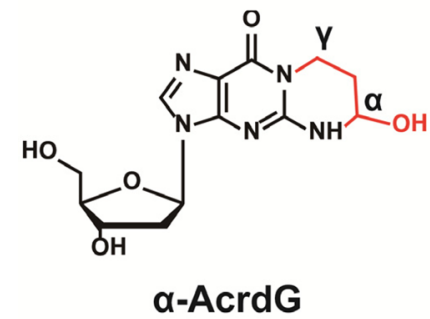

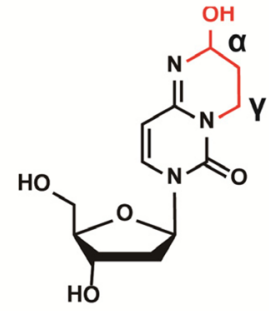

$\alpha-A c r d C$

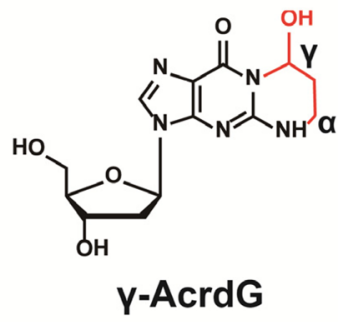

Figure 1. Chemical structures of Acr-DNA adducts studied in this work.

In addition to AcrdG, the adducts of $2^{\prime}$-deoxyadenosine, ${ }^{25-29}$ $2^{\prime}$-deoxycytidine, ${ }^{30,31}$ and thymidine ${ }^{32}$ were also identified, including 9-hydroxy-1, $N^{6}$-propano- $2^{\prime}$-deoxyadenosine $(\alpha$ AcrdA $)^{28-28}$ and 9-hydroxy-3, $N^{4}$-propano-2'-deoxycytidine $(\alpha$-AcrdC $){ }^{31}$ Although these non-dG adducts have been identified in naked DNA or cultured cells treated by Acr, it is unclear whether they are present in human tissues and their fate and genotoxicity are also unknown.

Several approaches for the detection of AcrdG have been developed, including ${ }^{32} \mathrm{P}$-postlabeling, ${ }^{20-22}$ immunoassays, ${ }^{33,34}$ and LC-MS/MS. ${ }^{13,23,24}$ Due to its advantages in specificity, structural characterization, separation efficiency, and safety, LCMS/MS is of choice. By taking advantage of nano-LC and nanospray-enhanced MS detection, a highly sensitive method for simultaneous detection of AcrdG adducts was developed. ${ }^{23}$ However, one stereoisomer of $\alpha$-AcrdG coeluted with $\gamma$-AcrdG. The same problem also faced in the capillary LC-MS/MS method. ${ }^{13}$ On the other hand, without the application of nanoflow and nanospray technologies that are not widely applicable, highly sensitive detection has not been achieved yet. Moreover, no assay was reported to detect AcrdA and $\mathrm{dC}$ adducts in human tissues.

The objectives of this study are (1) to improve the ESI-MS detection of Acr-DNA adducts by enhancing protonation, (2) to improve the separation of Acr adducts and their structural isomers and stereoisomers, and (3) to accurately quantify $\alpha$ AcrdG, $\gamma$-AcrdG, $\alpha$-AcrdA, and $\alpha$-AcrdC in human tissues by the use of stable isotope as internal standard. Therefore, we synthesized the stable isotope standards of Acr-DNA adducts, investigated the ESI-MS detection and UHPLC separation of DNA adducts, and tested the abundance of Acr-dG and non$\mathrm{dG}$ adducts in human leukocytes.

\section{EXPERIMENTAL SECTION}

Caution: Acr is highly mutagenic and should be handled with caution.

Chemicals and Materials. Acr was ordered from Aladdin (Shanghai, China). 2'-Deoxyguanosine monohydrate $\left(\mathrm{dG} \cdot \mathrm{H}_{2} \mathrm{O}\right), 2^{\prime}$-deoxyadenosine monohydrate $\left(\mathrm{dA} \cdot \mathrm{H}_{2} \mathrm{O}\right), 2^{\prime}$ deoxycytidine $(\mathrm{dC})$, snake venom phosphodiesterase I, and ammonium bicarbonate were obtained from Sigma-Aldrich Co. (St. Louis, MO). Ammonium formate and ammonium acetate were purchased from Agilent (Palo Alto, CA) and Signopharm Chemical Reagent Co. (Beijing, China), respectively. Deoxyribonuclease I (DNase I) and calf intestinal alkaline phosphatase (CIP) were obtained from New England Biolabs (Ipswich, MA).

Synthesis of Stable Isotopic Standards of Acr-DNA Adducts. Each Acr-DNA standard was prepared by the direct reaction of Acr with the corresponding 2'-deoxyribonucleoside (with or without stable isotopic label). In brief, $\mathrm{dG}, \mathrm{dA}$, or $\mathrm{dC}$ was separately incubated with an equal mole equivalent of Acr in $50 \mathrm{mM}$ phosphate buffer, $\mathrm{pH} 7.0$ at $37{ }^{\circ} \mathrm{C}$ for $48 \mathrm{~h}$, and the products were purified by reversed-phase HPLC. The collected fractions were dried by lyophilization and then were weighed with a Mettler Toledo XS 105 Analytical Balance (Greifensee, Switzerland). All the Acr-DNA standards were characterized by ESI-MS/MS and quantitated by UV at their maximum absorption wavelength $(257 \mathrm{~nm}$ for AcrdG; $261 \mathrm{~nm}$ for $\alpha$ AcrdA; $281 \mathrm{~nm}$ for $\alpha$-AcrdC).

UHPLC-ESI-MS/MS Analysis. The UHPLC-MS/MS analysis was performed on Agilent 1290 UHPLC system coupled with a G6410B triple quadrupole mass spectrometer (Agilent Technologies, Palo Alto, CA). Zorbax Eclipse Plus C18 column $(100 \mathrm{~mm} \times 2.1 \mathrm{~mm}$ i.d., $1.8 \mu \mathrm{m}$ particle size, Agilent Technologies, Palo Alto, CA) was used for separation of modified 2'-deoxyribonucleoside. The optimized mobile phase consisted of two solvents: $10 \mathrm{mM} \mathrm{NH} \mathrm{HCO}_{3}, \mathrm{pH} 9.0$ (solvent $\mathrm{A})$, and pure methanol (solvent $\mathrm{B}$ ). An optimized gradient elution was used for UHPLC separation: 0-6 min, 5\% B; 6-10 $\min , 15 \% \mathrm{~B} ; 10-15 \mathrm{~min}, 5 \% \mathrm{~B}$. The flow-rate was $0.25 \mathrm{~mL} /$ min, and the column temperature was set at $30{ }^{\circ} \mathrm{C}$. We also tested formic acid $(0.1 \%, 0.01 \%$, and $0.001 \%)$ and three volatile ammonium buffers $(0.5-10 \mathrm{mM})$ as an additive to the mobile phase.

The mass spectrometer was operated in the positive ion mode. A multiple reaction monitoring (MRM) mode was adopted for selective detection of the Acr-DNA adducts: $m / z$ $324 \rightarrow 208$ for AcrdG (collision energy, $5 \mathrm{eV}$ ); $m / z 308 \rightarrow 192$ for $\alpha$-AcrdA $(15 \mathrm{eV})$, and $m / z 284 \rightarrow 168$ for $\alpha$-AcrdC $(5 \mathrm{eV})$; $m / z 329 \rightarrow 213$ for $\left[{ }^{15} \mathrm{~N}_{5}\right]$ AcrdG $(5 \mathrm{eV}), m / z 313 \rightarrow 179$ for $\left[{ }^{15} \mathrm{~N}_{5}\right] \alpha$-AcrdA $(35 \mathrm{eV})$, and $m / z 287 \rightarrow 171$ for $\left[{ }^{15} \mathrm{~N}_{3}\right] \alpha$ AcrdC $(5 \mathrm{eV})$. Nitrogen was used for nebulization and desolvation. The nebulization gas was set at $40 \mathrm{psi}$, the flowrate of desolvation gas was $9 \mathrm{~L} / \mathrm{min}$, and source temperature was set at $300{ }^{\circ} \mathrm{C}$. Capillary voltage was set at $3500 \mathrm{~V}$. High purity nitrogen (99.999\%) was used as the collision gas. Each sample was at least analyzed for three times with an injection volume of $15 \mu \mathrm{L}$. The adduct frequency was calibrated internally by the stable isotopic standards.

The separation resolution $\left(R_{\mathrm{s}}\right)$ was calculated following Chinese National Standards (GB4946-85) as below.

$$
R_{\mathrm{s}}=2 \times\left(t_{R, 2}-t_{R, 1}\right) /\left(t_{w, 1}+t_{w, 2}\right)
$$

where $t_{\mathrm{R}, 1}$ and $t_{\mathrm{R}, 2}$ are the respective retention time of peaks 1 and 2 , and $t_{\mathrm{w}, 1}$ and $t_{\mathrm{w}, 2}$ are the respective peak widths of peaks 1 and 2.

Calibration Curves and Recovery. Calibration curves were constructed using the prepared standards of Acr adducts. The stable isotopic standards of a constant amount were mixed with nonisotope Acr adducts of varying amounts, and then the mixtures were analyzed by UHPLC-MS/MS. Calibration curves were obtained by linearly plotting the peak area ratios of 
nonisotope Acr adducts to the stable isotopic standards versus the amount of the added nonisotopic Acr adducts.

The recovery was tested by measuring the content of adducts in A549 genomic DNA spiked with the known amounts of Acr standards (1.5, 4.5, and $15 \mathrm{fmol}$ ) and calculated according to the formula shown below.

$$
\text { recovery } \%=(\text { the measured level }- \text { the background level })
$$

$$
\text { /added amount } \times 100 \%
$$

A549 Cell Culture and DNA Extract. Human lung epithelial carcinoma A549 cells $\left(5 \times 10^{5}\right.$ cells/dish $)$ were seeded in $10 \mathrm{~cm}$ plastic dishes (Corning, NY) and cultured in $10 \mathrm{~mL}$ (per dish) RPMI 1640 growth medium supplemented with $10 \%$ fetal bovine serum (Invitrogen, Carlsbad, CA), containing $100 \mathrm{U} / \mathrm{mL}$ penicillin $\mathrm{G}$ and $100 \mathrm{U} / \mathrm{mL}$ streptomycin sulfate. The dishes were put in a humidified 37 ${ }^{\circ} \mathrm{C}$ incubator supplied with $5 \% \mathrm{CO}_{2}$. After the A549 cells were cultured for $48 \mathrm{~h}$, the genomic DNA was extracted with the Promega Wizard genomic DNA purification kit according to the manufacturer's instructions. The isolated DNA was airdried and stored at $-20{ }^{\circ} \mathrm{C}$ prior to enzymatic digestion.

Genomic DNA Isolation from Human Leukocytes. Human blood samples were kindly provided by five volunteers. Freshly drawn human blood was stored at $4{ }^{\circ} \mathrm{C}$ in the presence of $10 \%(\mathrm{v} / \mathrm{v})$ citrate-dextrose solution as anticoagulant. Red blood cells were lysed by addition of cell lysis solution, and the leucocyte pellets were obtained by centrifuging the mixture at $12000 \mathrm{rpm}$ for $1 \mathrm{~min}$ at room temperature.

Genomic DNAs were extracted from the isolated leucocytes with the Promega Wizard genomic DNA purification kit. The extracted genomic DNA was redissolved in $50 \mu \mathrm{L}$ of water. The amount of genomic DNA was determined at $260 \mathrm{~nm}$ using Nanodrop 2000 by assuming that 1.0 OD equals $50 \mu \mathrm{g} / \mathrm{mL}$. The DNA samples (20 $\mu \mathrm{g}$ each) were mixed with a known amount of $\left[{ }^{15} \mathrm{~N}\right]$ Acr-DNA and digested with 2.0 units of DNase I, 4.0 units of CIP, and 0.008 units of snake venom phosphodiesterase I at $37{ }^{\circ} \mathrm{C}$ for $12 \mathrm{~h}$. The total volume was $100 \mu \mathrm{L}$. The enzymatic digests were filtered by ultrafiltration tubes (MW cutoff: $3 \mathrm{KDa}$, Pall, Port Washington, NY) to remove the enzymes and then analyzed by UHPLC-ESI-MS/ MS. Note, the DNA samples were stored at $-20{ }^{\circ} \mathrm{C}$ prior to enzymatic digestion.

\section{RESULTS AND DISCUSSION}

Ammonium Bicarbonate Improves the Separation of the Structural Isomers and Stereoisomers of AcrdG. We first optimized the separation of Acr-dG adducts and their isomers by a reversed-phase UHPLC. By adding $0.1 \%$ formic acid into the mobile phase, we observed that the peaks of AcrdG isomers are broadened and cannot be well resolved (Figure 2a). The two stereoisomers of $\alpha$-AcrdG are coeluted with $\gamma$-AcrdG. When the concentration of formic acid is reduced to $0.001 \%$, the two stereoisomers of $\alpha$-AcrdG are completely separated, but one stereoisomer of $\alpha$-AcrdG (with longer retention) could not be well resolved from $\gamma$-AcrdG $\left(R_{3,2}\right.$ $<0.8)$. For all the tested concentrations of formic acid, the peak of $\gamma$-AcrdG is broadened (Figure 2a). The separation of $\alpha$ AcrdG and $\gamma$-AcrdG can be markedly improved with any tested ammonium salt (formate, acetate, or bicarbonate salt) (Figure $2 \mathrm{~b})$. The optimum separation of $\alpha$-AcrdG and $\gamma$-AcrdG can be obtained with ammonium bicarbonate $\left(R_{3,2}=1.7\right)$. However,
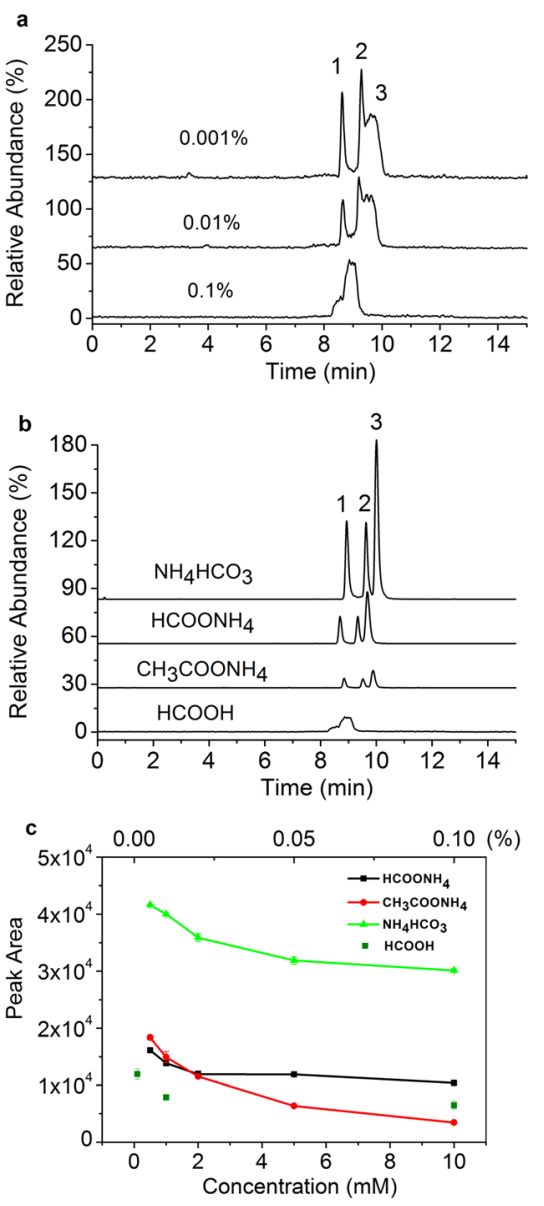

Figure 2. The effects of mobile-phase additives on the UHPLC separation of and MS detection sensitivity to Acr-dG isomers. (a) The UHPLC separation of $\alpha$-AcrdG and $\gamma$-AcrdG using $\mathrm{HCOOH}$ as an additive to the mobile phase. Peaks 1 and 2 represent the two stereoisomers of $\alpha$-AcrdG, and peak 3 is $\gamma$-AcrdG. (b) The separation of AcrdG isomers was obtained by using one additive $\left(\mathrm{NH}_{4} \mathrm{HCO}_{3}\right.$, $\mathrm{HCOONH}_{4}, \mathrm{CH}_{3} \mathrm{COONH}_{4}$, or $\mathrm{HCOOH}$ ) in the mobile phase as indicated in the figure. (c) The plots of the peak area of AcrdG standards (10 $\mathrm{nM}$ for each isomer) against the concentration of the additive ammonium salt $(0.5-10 \mathrm{mM})$ or $\mathrm{HCOOH}(0.001 \%-0.10 \%)$ as indicated. The peak areas were estimated as the sum of peaks 1-3. The mobile phases consisted of two solvents A and B (pure methanol). Solvent A: $10 \mathrm{mM}$ ammonium salt or $0.001-0.1 \%(\mathrm{v} / \mathrm{v})$ $\mathrm{HCOOH}$ in water. Gradient elution was used: $0-6 \mathrm{~min}, 5 \% \mathrm{~B} ; 6-10$ $\min , 15 \% \mathrm{~B} ; 10-15 \mathrm{~min}, 5 \% \mathrm{~B}$. The other chromatographic conditions are described in Experimental Section.

ammonium acetate $\left(R_{3,2}=1.4\right)$ and ammonium formate $\left(R_{3,2}=\right.$ 1.2) can provide satisfactory separation.

Ammonium Bicarbonate Enhances the MS Detection of AcrdG Isomers. By including ammonium bicarbonate as an additive of the mobile phase, we found that ammonium bicarbonate can greatly enhance the MS detection of AcrdG isomers no matter whether the MS signal is evaluated by peak height or peak area (Figure 2b). Even involved with high concentrations of the additive $(5-10 \mathrm{mM})$, ammonium bicarbonate can enhance the MS detection of AcrdG isomers (Figure 2c). Compared with ammonium formate and ammonium acetate in the same concentration range, ammonium bicarbonate can increase the MS signals of all AcrdG isomers significantly by $2.3-8.7$ times (Figure $2 \mathrm{~b}$ and $2 c)$. In contrast to formic acid, ammonium bicarbonate also 
increases the MS detection of AcrdG isomers by 5.2 fold ( 10 $\mathrm{mM} \mathrm{NH}_{4} \mathrm{HCO}_{3}$ vs $0.1 \% \mathrm{HCOOH}$ ).

To explore the mechanism of the enhancement of MS detection by ammonium bicarbonate, the UHPLC fractions of AcrdG are directly scanned from $\mathrm{m} / z 100$ to 380 in the positive ion mode by ESI-triple quadrupole mass spectrometer. Figure 3
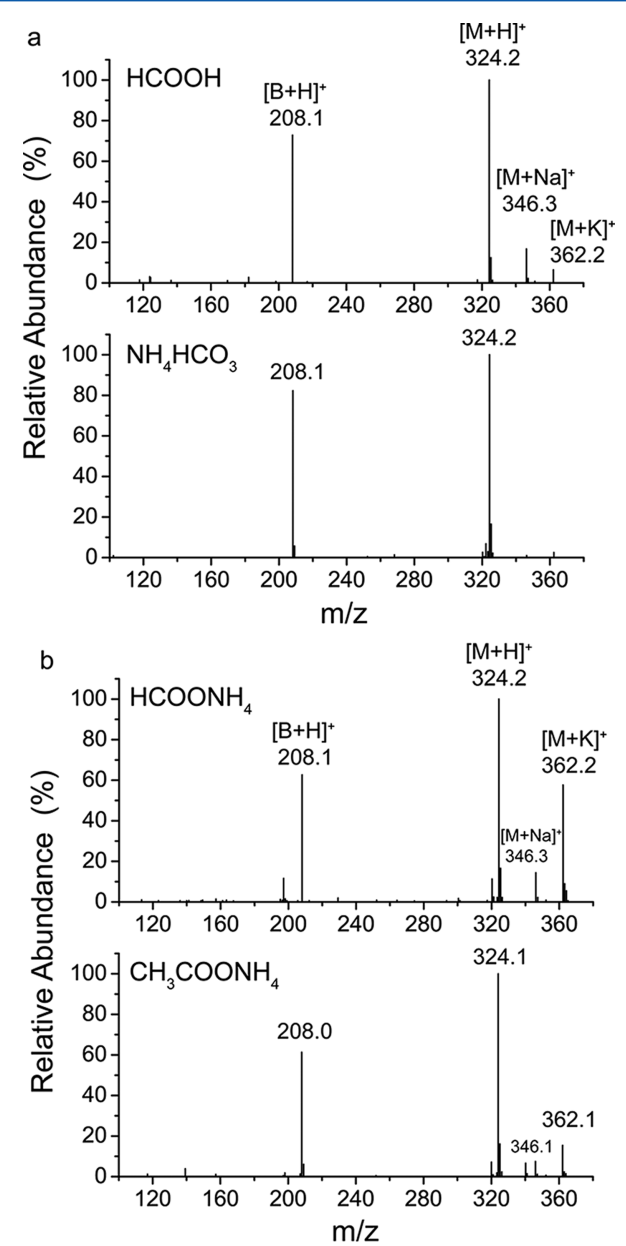

Figure 3. The typical ESI-MS spectra of AcrdG isomers were obtained when different additives to the mobile phase were used. The concentrations of $\mathrm{NH}_{4} \mathrm{HCO}_{3}, \mathrm{HCOONH}_{4}$, and $\mathrm{CH}_{3} \mathrm{COONH}_{4}$ in mobile phase A were kept at $10 \mathrm{mM}$, and $\mathrm{HCOOH}$ was kept at $0.1 \%$ $(\mathrm{v} / \mathrm{v})$.

shows the formation of $[\text { AcrdG }+\mathrm{Na}]^{+}$and $[\text {AcrdG }+\mathrm{K}]^{+}$ complexes by using $\mathrm{HCOOH}, \mathrm{HCOONH}_{4}$, or $\mathrm{CH}_{3} \mathrm{COONH}_{4}$ as an additive to the mobile phase. By assuming that the abundance of $[$ AcrdG] is $100 \%$, the metal-AcrdG complexes account for $22.8-72 \%$. Regarding the instability of these metal complexes during ESI-MS detection, the observation of metal complexes at an un-neglected ratio may indicate the formation of paramount metal complexes during the ESI process, which will significantly deteriorate the MS detection. ${ }^{35}$ Interestingly, the metal-AcrdG complexes significantly reduce down to $3.6 \%$ by using $\mathrm{NH}_{4} \mathrm{HCO}_{3}$ as an additive. These data suggest that ammonium bicarbonate can suppress the formation of MS signal-deteriorating metal-AcrdG complexes during the ESI process. Probably, ammonium group of $\mathrm{NH}_{4} \mathrm{HCO}_{3}$ may form ionic complexes with AcrdG, which can be further deammonized to form protonated AcrdGs during the ionization process presumably in a heated gas phase. Meanwhile, the $\mathrm{HCO}_{3}{ }^{-}$may form carbonic acid and thermally degrade to carbon dioxide and water. This process is expected to favor the protonation of AcrdG isomers. This mechanism should not be limited to AcrdG, and we found that a number of modified 2'deoxyribonucleosides can benefit from this enhancement mechanism (unpublished data). Therefore, we provide a general method for enhancing ESI-MS detection of modified 2 -deoxyribonucleosides that have difficulty in protonation due to the formation of excess metal complexes during the ionization process.

Separation and Detection of 8-oxodG and $\alpha$-AcrdC. Unexpectedly, oxidatively generated damage 8-oxo-7,8-dihydro2 -deoxyguanosine (8-oxodG), which is unavoidably present in genomic DNA, may have the same chromatographic retention as $\alpha$-AcrdC when ammonium bicarbonate is included in the mobile phase (Figure 4a). Moreover, 8 -oxodG and $\alpha$-AcrdC have the same molecular weight $(283 \mathrm{Da})$ and same MRM transition $(m / z 284 \rightarrow 168)$ for sensitive MS/MS detection. Therefore, the overlapped peaks of 8 -oxodG and $\alpha$-AcrdC cannot be indirectly resolved by MS detection without separation. In light of this problem, we optimized the $\mathrm{pH}$ of the mobile phase without sacrificing the MS detection sensitivity. This was achieved by titration of the mobile phase with ammonia. We found that, by increasing the $\mathrm{pH}$ to 9.0, the peak of $\alpha$-AcrdC will have stronger retention than the two peaks of 8 -oxodG (Figure $4 \mathrm{~b}$ ), rendering satisfactory separation.

Consistent with previous work, ${ }^{36}$ two peaks (peaks 1 and 2 ) were observed as assigned to 8 -oxodG in Figure $4 \mathrm{a}$ and $4 \mathrm{~b}$. The first peak of 8-oxodG has the same chromatographic retention pattern as that of $\mathrm{dG}$ regardless of the change in the stationary and mobile phases of UHPLC (data not shown), assuming it is the product of the spontaneous oxidation of $\mathrm{dG}$ during the ESI process. The injection of authentic dG also generated this peak, further supporting the peak assignment. The second peak of 8oxodG has the same chromatographic retention as that of standard 8-oxodG and is assigned to 8-oxodG present in genomic DNA (data not shown).

Calibration Curves, Limits of Detection (LOD), and Recovery. The obtained calibration curves are shown in Table 1. Excellent linearity for each Acr-DNA adduct (correlation coefficient: $R^{2} \geq 0.998$ ) is achieved with a dynamic range of 0.15-15 fmol. The LODs of these adducts $(S / N=3)$ are estimated to be about 40 amol except for $\alpha$-AcrdG because $\alpha$ AcrdG can be split into two peaks and thus has a higher LOD (80 amol, Table 1$)$.

The recovery is measured by spiking A549 DNA with the known amounts of standard Acr adducts. By deducting the corresponding control level, the estimated recovery for the added adducts ranges from 83 to $92 \%$ for $\alpha$-AcrdA, 84 to $99 \%$ for $\alpha$-AcrdC, 85 to $95 \%$ for $\alpha$-AcrdG, and 81 to $97 \%$ for $\gamma$ AcrdG (Table 2).

Acr-DNA Adducts in A549 Cells. We further applied the developed UHPLC-MS/MS assay to the quantification of AcrDNA adducts in cultured A549 cells. Both $\alpha$-AcrdG and $\gamma$ AcrdG are detected in A549 cells (Figure 5a), which is not treated with any Acr. The mean frequency of $\gamma$-AcrdG $(15 \pm 3$ adducts per $\left.10^{8} \mathrm{nts}\right)$ is 4 times higher than that of $\alpha$-AcrdG (3.5 \pm 0.8 adducts in $10^{8}$ nts) (Table 3 ). The observed peaks of AcrdG in A549 DNA $(\mathrm{m} / z 324 \rightarrow 208)$ are further validated by spiking with the nonisotope standards of $\alpha$-AcrdG and $\gamma$-AcrdG (Figure $5 b$ ). Although it is a minor adduct, $\alpha$-AcrdG is $>10$ times more mutagenic than $\gamma$-AcrdG. ${ }^{37}$ Surprisingly, the signal 

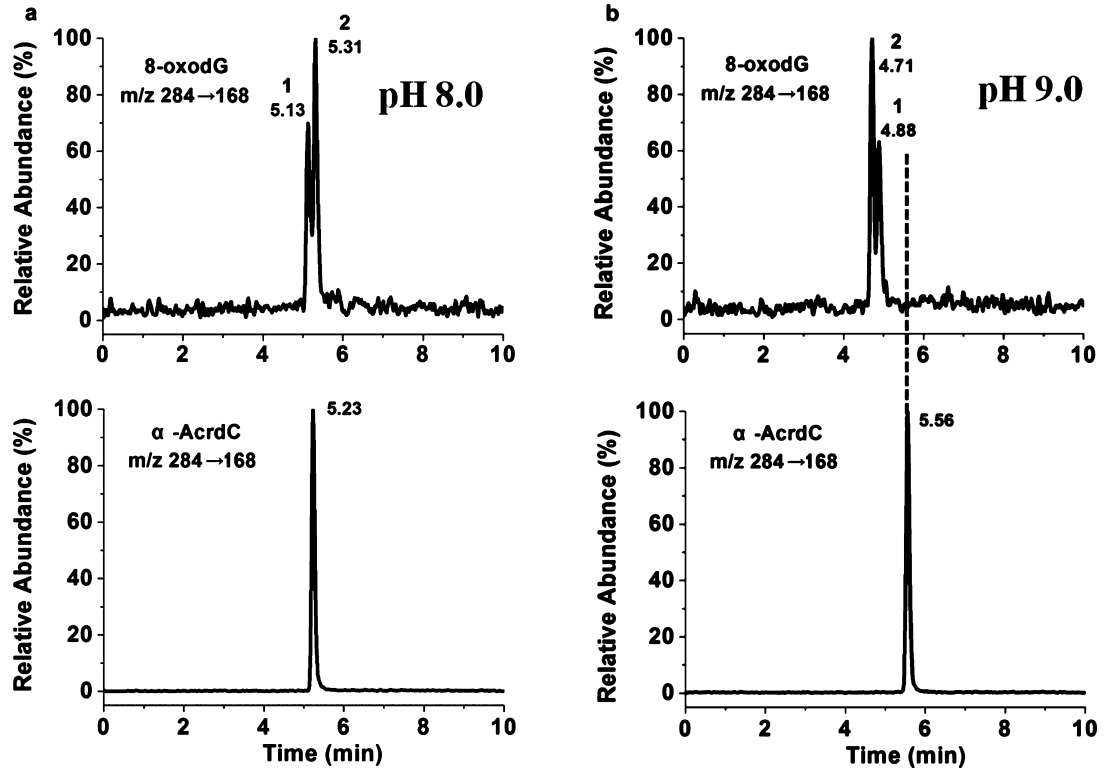

Figure 4. The effects of $\mathrm{pH}$ of mobile phase A on the separation of $\alpha$-AcrdC and 8-oxodG. Mobile phase A consisted of $10 \mathrm{mM} \mathrm{NH}_{4} \mathrm{HCO}_{3}, \mathrm{pH}^{8.0}$ (a), $10 \mathrm{mM} \mathrm{NH}_{4} \mathrm{HCO}_{3}$ adjusted to $\mathrm{pH} 9.0$ by $\mathrm{NH}_{3} \cdot \mathrm{H}_{2} \mathrm{O}$ (b). A $5.0 \mu \mathrm{L}$ volume of the mixture of $10.0 \mathrm{nM} \alpha$-AcrdC, $10.0 \mathrm{nM} \mathrm{8-oxodG}$, and $100 \mathrm{nM}$ $\mathrm{dG}$ were each injected. Gradient elution was used: 0-3 min, 5\% B (methanol); 3-8 min, $15 \% \mathrm{~B} ; 8-15 \mathrm{~min}, 5 \% \mathrm{~B}$. The flow rate is $0.25 \mathrm{~mL} / \mathrm{min}$, and the column temperature is set at $30^{\circ} \mathrm{C}$. Peak 1 is 8-oxodG from the spontaneous oxidation of dG in the ESI source, and peak 2 represents 8 oxodG generated in genomic DNA.

Table 1. Dynamic Range, Linearity, and LOD of Acr-DNA Adducts by UHPLC-MS/MS Analysis

\begin{tabular}{|c|c|c|c|c|}
\hline analyte & $\begin{array}{l}\text { dynamic range } \\
(\text { fmol })\end{array}$ & linearity & $R^{2}$ & $\begin{array}{l}\text { LOD } \\
(\mathrm{amol})\end{array}$ \\
\hline $\begin{array}{l}\alpha- \\
\text { AcrdA }\end{array}$ & $0.15-15$ & $y=0.0575 x-0.0066$ & 0.999 & 40 \\
\hline$\alpha-$ & $0.15-15$ & $y=0.0570 x-0.0117$ & 0.999 & 40 \\
\hline${ }^{\alpha-}$ AcrdG & $0.15-15$ & $y=0.0869 x-0.0217$ & 0.998 & 80 \\
\hline$\gamma$-AcrdG & $0.15-15$ & $y=0.0885 x-0.0156$ & 0.999 & 40 \\
\hline
\end{tabular}

Table 2. Recovery of the UHPLC-MS/MS Method for Determination of Acr-DNA Adducts in A549 DNA

\begin{tabular}{lcccc} 
& $\alpha$-AcrdA (\%) & $\alpha$-AcrdC (\%) & $\alpha$-AcrdG (\%) & $\gamma$-AcrdG (\%) \\
$1.5 \mathrm{fmol}$ & $83 \pm 4$ & $99 \pm 4$ & $94 \pm 6$ & $97 \pm 9$ \\
$4.5 \mathrm{fmol}$ & $85 \pm 2$ & $84 \pm 2$ & $95 \pm 7$ & $86 \pm 2$ \\
$15 \mathrm{fmol}$ & $92 \pm 4$ & $87 \pm 1$ & $85 \pm 5$ & $81 \pm 1$ \\
\hline
\end{tabular}

of the second stereoisomer $(10.0 \mathrm{~min})$ of $\alpha$-AcrdG is much smaller than that of the first one $(9.3 \mathrm{~min})$ (bottom trace in Figure 5a). This is also true for the stereoisomers of isotopic and nonisotopic standards of the $\alpha$-AcrdG when spiked with the digested genomic DNA (top trace in Figure 5a and top and bottom traces in Figure $5 b$ ). The exact reason is not clear, but we speculated that it is probably due to the ionization suppression by other unseen fractions that are coeluted with the second stereoisomer during the ESI process.

Both AcrdC and AcrdA adducts are detected in untreated A549 cells (Figure $5 \mathrm{c}-\mathrm{f}$ ). The level of $\alpha$-AcrdC is $3.6 \pm 0.3$ adducts per $10^{8} \mathrm{nts}$, while $\alpha$-AcrdA is the least adduct $(1.4 \pm$ 0.3 adducts per $10^{8}$ nts, Table 3 ). The two non-dG adducts in A549 cells $(m / z 284 \rightarrow 168$ and $308 \rightarrow 192)$ are also validated by spiking corresponding standard (Figure $5 \mathrm{~d}$ and $5 \mathrm{f}$ ). It is clear that both $\alpha$-AcrdC and $\alpha$-AcrdA can be detected in genomic DNA from cultured human A549 cells without Acr treatment, implicating the spontaneous generation of non-dG adducts in cultured human cells, which are probably attributed to metabolic processes.

Quantification of Acr-DNA Adducts in Human Leukocytes. It is known that AcrdG isomers were found in various human tissues, including lung, liver, brain, placenta, and leukocytes. However, it is not clear whether the non-dG adducts discussed above are present in human tissues, although they are detected in cultured human A549 cells as described above. So we further characterized the Acr adducts in human leukocytes by employing the developed UHPLC-MS/MS method.

The major adduct $\gamma$-AcrdG is detectable in all the genomic DNA samples of extracted human leukocytes $(n=5$, Table 3$)$. The adduct level ranges from 7.5 to 11 adducts per $10^{8}$ nts for $\gamma$-AcrdG, and the mean level is about $9.0 \pm 1.3$ adducts per $10^{8}$ nts. $\alpha$-AcrdG is detected only in two subjects with a much lower level than that of $\gamma$-AcrdG (ND-3.3 adducts in $10^{8} \mathrm{nts}$ ). These results are consistent with previous reports. ${ }^{23}$

$\alpha$-AcrdA is detected in all five leukocyte samples with a frequency of 2.5-20 adducts per $10^{8} \mathrm{nts}$, and the mean adduct level is $8.7 \pm 6.6$ adducts per $10^{8}$ nts. Obviously, the level of $\alpha$ AcrdA in leukocytes is comparable to that of $\gamma$-AcrdG and is much higher than that in A549 cells $\left(1.4 \pm 0.3\right.$ adducts per $10^{8}$ nts). Another non-dG adduct AcrdC is detected in three leukocyte samples with a frequency of about ND-16 adducts per $10^{8}$ nts.

In this study, we demonstrate that ammonium bicarbonate can enhance the protonation of AcrdG and suppress the formation of metal-AcrdG complexes, thereby improving the MS detection. Due to the enhancement of MS detection, even without the use of nano-LC and nano-ESI, the LODs ( $/ \mathrm{N}=$ 3) for detection of Acr adducts by our approach are estimated about 40-80 amol, which are comparable to that of nano-LCMS/MS. ${ }^{23}$ This is the first report showing the enhancement of MS detection of modified $2^{\prime}$-deoxyribonucleoside by ammo- 

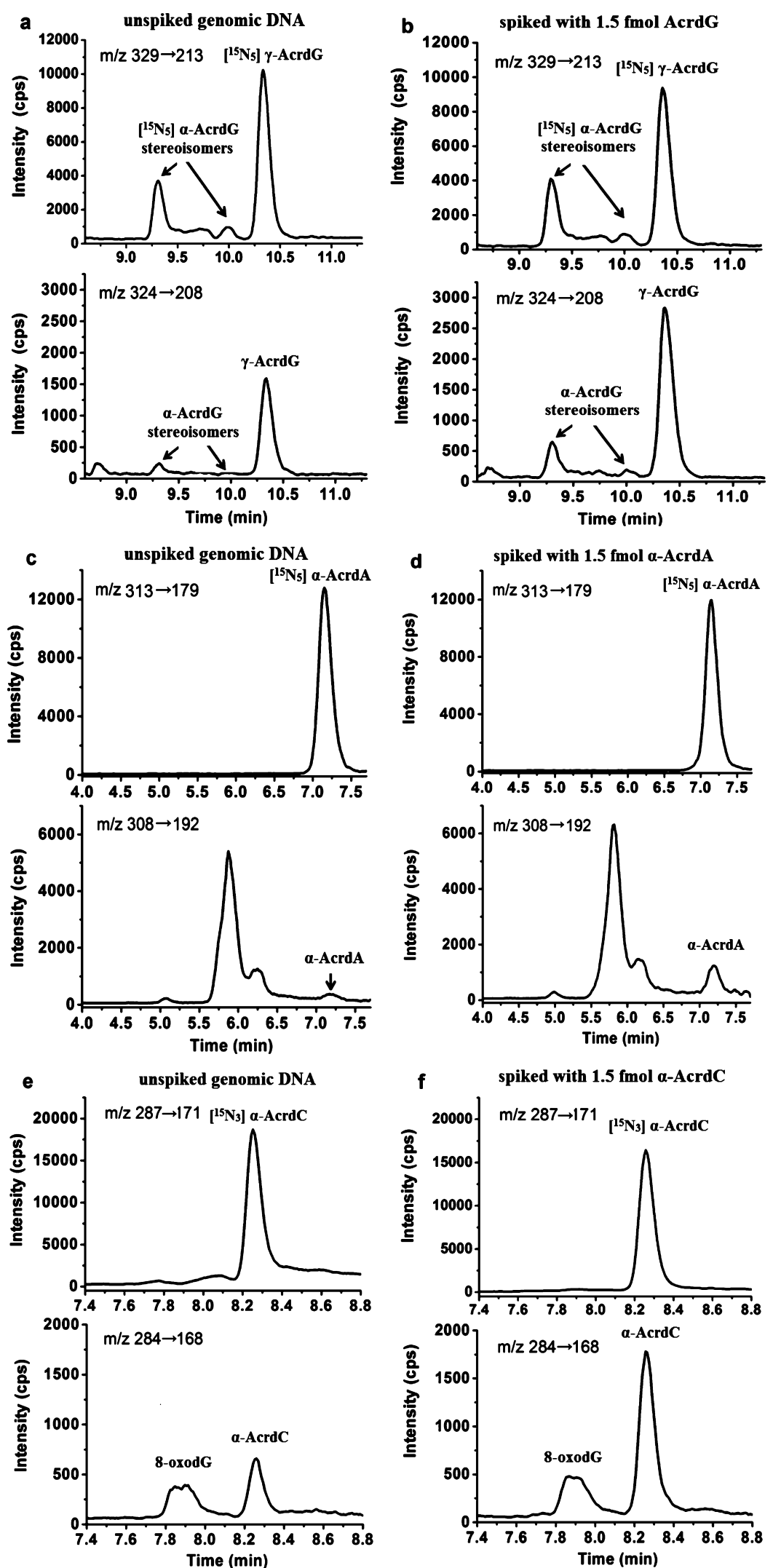

Figure 5. UHPLC-MS/MS chromatograms obtained from analysis of A549 DNA for detection of Acr-DNA adducts. The chromatograms a, c, and e obtained from the unspiked genomic DNA, and $b$, $d$, and $\mathrm{f}$ from the genomic DNA spiked with 1.5 fmol standard Acr adducts (as indicated) to confirm the identity of each Acr-DNA adduct in A549 DNA. The optimized chromatographic conditions were used, and the details are described in Experimental Section. 
Table 3. Quantitation of Acr-DNA Adducts in Genomic DNA from A549 and Human Leukocytes

\begin{tabular}{|c|c|c|c|c|c|c|}
\hline \multirow[b]{2}{*}{ sample } & \multirow[b]{2}{*}{ gender } & \multirow[b]{2}{*}{ amount of DNA $(\mu \mathrm{g})$} & \multicolumn{4}{|c|}{ Acr-DNA level (adducts per $10^{8}$ bases) } \\
\hline & & & $\alpha$-AcrdA & $\alpha$-AcrdC & $\alpha$-AcrdG & $\gamma$-AcrdG \\
\hline A549 & - & 20 & $1.4 \pm 0.3$ & $3.6 \pm 0.3$ & $3.5 \pm 0.8$ & $15 \pm 3.4$ \\
\hline 1 & male & 18 & $8.0 \pm 0.4$ & $6.2 \pm 0.3$ & $1.8 \pm 0.7$ & $8.4 \pm 0.5$ \\
\hline 2 & female & 13 & $2.5 \pm 0.3$ & $\mathrm{ND}^{a}$ & ND & $9.3 \pm 0.8$ \\
\hline 3 & male & 12 & $8.7 \pm 0.3$ & $6.8 \pm 0.2$ & ND & $11 \pm 0.8$ \\
\hline 4 & female & 9 & $4.8 \pm 0.2$ & ND & ND & $8.8 \pm 0.6$ \\
\hline 5 & male & 9 & $20 \pm 0.3$ & $16 \pm 0.8$ & $3.3 \pm 0.7$ & $7.5 \pm 0.2$ \\
\hline $\operatorname{mean}^{b}$ & & & $8.7 \pm 6.6$ & & & $9.0 \pm 1.3$ \\
\hline
\end{tabular}

${ }^{a}$ ND indicates "undetectable". ${ }^{b}$ Calculated from samples 1 to 5, not including the A549 DNA sample. Each sample was analyzed at least three times.

nium bicarbonate. In contrast, the other ammonium salts do not have this enhancement effect. These improvements allow us to accurately determine the levels of each isomer of AcrdG.

By employing the developed sensitive method, $\alpha$-AcrdG is found in cultured human cells even without Acr treatment. Although its level is just comparable to $30 \%$ of $\gamma$-AcrdG, $\alpha$ AcrdG should be paid more attention regarding its higher mutation potency. Besides AcrdG isomers, non-dG adducts (AcrdA and AcrdC) are also found in untreated A549 cells and leukocytes. Some non-dG adducts $(\alpha$-AcrdA) may be present at levels even comparable to that of the predominant $\gamma$-AcrdG. These results may suggest that the Acr-DNA adducts can be spontaneously generated through normal cellular metabolism.

\section{CONCLUSIONS}

We developed a sensitive and accurate method for simultaneous quantification of $\alpha$-AcrdG (two stereoisomers), $\gamma$-AcrdG, $\alpha$-AcrdC, and $\alpha$-AcrdA in human cells using stable isotope dilution UHPLC-MS/MS, which only requires $3 \mu \mathrm{g}$ of genomic DNA for each analysis. We also demonstrate that ammonium bicarbonate not only improves the separation of the Acr-DNA adducts and their isomers but also enhances the MS detection of modified 2 '-deoxyribonucleosides with difficulty in protonation during the ESI process.

\section{AUTHOR INFORMATION}

\section{Corresponding Author}

*E-mail: hlwang@rcees.ac.cn.

\section{Notes}

The authors declare no competing financial interest.

\section{ACKNOWLEDGMENTS}

This work was supported by grants from the National Basic Research Program of China (2011CB936001, 2009CB421065, and 2011YQ060084) and the National Natural Science Foundation of China $(21077129,20890112$, and 21125523).

\section{REFERENCES}

(1) Stevens, J. F.; Maier, C. S. Mol. Nutr. Food Res. 2008, 52, 7-25.

(2) Hecht, S. S. Proc. Natl. Acad. Sci. U.S.A. 2006, 103, 15725-15726.

(3) Ho, S. S.; Yu, J. Z.; Chu, K. W.; Yeung, L. L. J. Air Waste Manage. Assoc. 2006, 56, 1091-1098.

(4) A comprehensive analysis of biodiesel impacts on exhaust emissions, Draft Technical Report, United States Environmental Protection Agency, 2002.

(5) Feng, Z.; Hu, W.; Hu, Y.; Tang, M. S. Proc. Natl. Acad. Sci. U.S.A. 2006, 103, 15404-15409.

(6) Chung, F. L.; Chen, H. J.; Nath, R. G. Carcinogenesis 1996, 17, $2105-2111$
(7) Uchida, K.; Kanematsu, M.; Morimitsu, Y.; Osawa, T.; Noguchi, N.; Niki, E. J. Biol. Chem. 1998, 273, 16058-16066.

(8) Anderson, M. M.; Hazen, S. L.; Hsu, F. F.; Heinecke, J. W. J. Clin. Invest. 1997, 99, 424-432.

(9) O’Brien, P. J.; Siraki, A. G.; Shangari, N. Crit. Rev. Toxicol. 2005, 35, 609-612.

(10) Williams, T. I.; Lynn, B. C.; Markesbery, W. R.; Lovell, M. A. Neurobiol. Aging 2006, 27, 1094-1099.

(11) Bradley, M. A.; Markesbery, W. R.; Lovell, M. A. Free Radic. Biol. Med. 2010, 48, 1570-1576.

(12) Lovell, M. A.; Xie, C.; Markesbery, W. R. Neurobiol. Aging 2001, 22, 187-194.

(13) Liu, X.; Lovell, M. A.; Lynn, B. C. Anal. Chem. 2005, 77, 59825989.

(14) Uchida, K. Free Radic. Biol. Med. 2000, 28, 1685.

(15) Chung, F. L.; Young, R.; Hecht, S. S. Cancer Res. 1984, 44, 990995.

(16) Parent, R. A.; Caravello, H. E.; San, R. H. C. J. Appl. Toxicol. 1996, 16, 103-108.

(17) Marnett, L. J.; Hurd, H. K.; Hollstein, M. C.; Levin, D. E.; Esterbauer, H.; Ames, B. N. Mutat. Res. 1985, 148, 25-34.

(18) Kawanishi, M.; Matsuda, T.; Nakayama, A.; Takebe, H.; Matsui, S.; Yagi, T. Mutat. Res. 1998, 417, 65-73.

(19) Wang, H. T.; Zhang, S.; Hu, Y.; Tang, M. S. Chem. Res. Toxicol. 2009, 22, 511-517.

(20) Nath, R. G.; Chung, F. L. Proc. Natl. Acad. Sci. U.S.A. 1994, 91, $7491-7495$.

(21) Nath, R. G.; Ocando, J. E.; Chung, F. L. Cancer Res. 1996, 56, $452-456$

(22) Nath, R. G.; Ocando, J. E.; Guttenplan, J. B.; Chung, F. L. Cancer Res. 1998, 58, 581-584.

(23) Chen, H. J.; Lin, W. P. Anal. Chem. 2009, 81, 9812-9818.

(24) Zhang, S.; Villalta, P. W.; Wang, M.; Hecht, S. S. Chem. Res. Toxicol. 2007, 20, 565-571.

(25) Sodum, R.; Shapiro, R. Bioorg. Chem. 1988, 16, 272-282.

(26) Smith, R. A.; Williamson, D. S.; Cerny, R. L.; Cohen, S. M. Cancer Res. 1990, 50, 3005-3012.

(27) Pawiowicz, A. J.; Munter, T.; Klika, K. D.; Kronberg, L. Bioorg. Chem. 2006, 34, 39-48.

(28) Pawłowicz, A. J.; Munter, T.; Zhao, Y.; Kronberg, L. Chem. Res. Toxicol. 2006, 19, 571-576.

(29) Kawai, Y.; Furuhata, A.; Toyokuni, S.; Aratani, Y.; Uchida, K. J. Biol. Chem. 2003, 278, 50346-50354.

(30) Chenna, A.; Iden, C. R. Chem. Res. Toxicol. 1993, 6, 261-268.

(31) Pawłowicz, A. J.; Klika, K. D.; Kronberg, L. Eur. J. Org. Chem. 2007, 1429-1437.

(32) Pawłowicz, A. J.; Kronberg, L. Chem. Biodivers. 2008, 5, 177188.

(33) Foiles, P. G.; Akerkar, S. A.; Chung, F. L. Carcinogenesis 1989, 10, 87-90.

(34) McDiarmid, M. A.; Iype, T.; Kolodner, K.; Jacobson-Kram, D.; Strickland, P. T. Mutat. Res. 1991, 248, 93-99.

(35) Nordhoff, E.; Kirpekar, F.; Roepstorff, P. Mass Spectrom. Rev. 1996, 15, 67-138. 
(36) Frelon, S.; Douki, T.; Ravanat, J. L.; Pouget, J. P.; Tornabene, C.; Cadet, J. Chem. Res. Toxicol. 2000, 13, 1002-1010.

(37) Yang, I. Y.; Chan, G.; Miller, H.; Huang, Y.; Torres, M. C.; Johnson, F.; Moriya, M. Biochemistry 2002, 41, 13826-13832. 